\title{
Wheat-dependent Exercise-induced Anaphylaxis
}

\author{
Hakim Rahmoune $^{1,2, *}$, Nada Boutrid ${ }^{1,2}$, Mounira Amrane ${ }^{2,3}$, Tahar Kherkhache ${ }^{1}$, Belkacem Bioud ${ }^{1,2}$ \\ ${ }^{1}$ Department of Pediatrics, University Hospital of Setif, Setif-1 University, Algeria \\ ${ }^{2}$ Genetic, Cardiovascular \& Nutritional Diseases Laboratory, Setif-1 University, Algeria \\ ${ }^{3}$ Central Laboratory, CAC Hospital of Setif; Setif-1 University, Algeria \\ *Corresponding author: rahmounehakim@gmail.com
}

Received July 30, 2019; Revised September 03, 2019; Accepted December 04, 2019

\begin{abstract}
Gluten-related disorders are an emerging worldwide with a global prevalence estimated at $5 \%$ in the general population. They include celiac disease, nonceliac gluten sensitivity and wheat allergy. Specifically, the peculiar wheat-dependent exercise-induced anaphylaxis is a particular allergy that occurs after wheat ingestion followed by physical exercise.
\end{abstract}

Keywords: gluten, wheat, allergy

Cite This Article: Hakim Rahmoune, Nada Boutrid, Mounira Amrane, Tahar Kherkhache, and Belkacem Bioud, "Wheat-dependent Exercise-induced Anaphylaxis." International Journal of Celiac Disease, vol. 7, no. 3 (2019): 84-85. doi: 10.12691/ijcd-7-3-2.

\section{Introduction}

Gluten-related disorders are an emerging worldwide with an estimated prevalence as high as $5 \%$ in the general population. [1]

They include celiac disease, nonceliac gluten sensitivity and wheat allergy. The peculiar wheat-dependent exercise-induced anaphylaxis is a particular form of growing importance for patients with recurrent anaphylaxis.

Here is summarized and discussed the clinical presentation in a non-celiac boy.

\section{Case Presentation}

An 8-year-old child presented to the emergency department for acute dyspnea and wheezing. Physical examination revealed a labial angioedema and mild facial swelling.

According to his mother, these symptoms appeared shortly after good toasts of cereals at the same afternoon; a snack followed by a football match...

The boy underwent several allergy investigations, including skin prick \& patch tests to various allergens; along with respiratory functional exploration.

Gathering different anamnestic and clinical findings (chiefly the positive wheat prick test reaction), this patient was finally diagnosed as having an exercise-induced asthma induced by wheat, a very particular respiratory allergy induced by gluten and classified as a wheat-dependent exercise-induced anaphylaxis.

Afterward, celiac autoimmunity screening was done and was negative.

Eviction diet (gluten free) was started and follow-up in allergy out-patient clinic is ordered.

\section{Discussion}

Although rare, food-dependent, exercise-induced anaphylaxis (FDEIA) is an evolving spectrum, known as a distinct form of allergic reaction induced over by the ingestion of a causative food and subsequent physical exercise.

Clinically, anaphylaxis/allergic reaction develops several hours most predictably when exercise takes place within a few hours of ingesting a specific food. These reactions range from urticaria and angioedema to dyspnea, hypotension, collapse, and shock. Particularly, it is the combination of the food and exercise that precipitates attacks, whereas the food and exercise are each tolerated independently. [2,3]

Specifically, wheat-dependent exercise-induced anaphylaxis (WDEIA) is rare and potentially severe as food allergy exclusively occurs after wheat ingestion, usually symptomatic after wheat consumption followed by physical exercise. [5]

Wheat is the most widely reported among a number of foods associated with FDEIA: Wheat contains a wide variety of proteins and therefore potential allergens, and several forms are related to some of these allergens. $[6,7,8]$

Wheat proteins are categorized into four fractions (according to their solubility): water (albumins), dilute salt solutions (globulins), aqueous alcohol (gliadins), and dilute alkali or acid (glutelins). Overlap is described between the spectra of proteins responsible for diverse clinical conditions. [9]

Diagnosis of wheat allergy relies on a consistent history, skin prick tests and/or specific IgE tests. The accuracy of diagnosis may be improved by measuring IgE responses to several wheat components. [10]

Wheat allergy is now classified among the spectrum of gluten-related disorders (GRDs): an emerging worldwide 
problem of epidemiologically relevant conditions, with a global prevalence estimated at $5 \%$ in the general population. These conditions are related to gluten ingestion and include celiac disease, nonceliac gluten sensitivity and wheat allergy, including the peculiar wheat-dependent exercise-induced anaphylaxis. [1,11,12]

\section{Conclusion}

Beyond celiac disease, wheat may lead to several allergies with a myriad of signs: respiratory, digestive, cutaneous ...

Diagnosis should be assessed before introducing an eviction diet, as this allergy might be transient with an excellent outcome.

\section{Acknowledgements}

The authors would thank the outpatient allergy clinic (Department of Pediatrics, University Hospital of Setif) for technical support.

\section{References}

[1] Sapone A, Bai JC, Ciacci C, Dolinsek J, Green PH, Hadjivassiliou M, Kaukinen K, Rostami K, Sanders DS, Schumann M, Ullrich R. Spectrum of gluten-related disorders: consensus on new nomenclature and classification. BMC medicine. 2012 Dec; 10(1): 13.
[2] Feldweg AM. Food-dependent, exercise-induced anaphylaxis: diagnosis and management in the outpatient setting. The Journal of Allergy and Clinical Immunology: In Practice. 2017 Mar 1; 5(2): 283-8.

[3] Giannetti MP. Exercise-induced anaphylaxis: literature review and recent updates. Current allergy and asthma reports. 2018 Dec 1; 18(12): 72.

[4] Kim CW, Figueroa A, Park CH, Kwak YS, Kim KB, Seo DY, Lee HR. Combined effects of food and exercise on anaphylaxis. Nutrition research and practice. 2013 Oct 1; 7(5): 347-51.

[5] Panel NS. Guidelines for the diagnosis and management of food allergy in the United States: report of the NIAID-sponsored expert panel. Journal of Allergy and Clinical Immunology. 2010 Dec 1; 126(6): S1-58.

[6] Mäkelä MJ, Eriksson C, Kotaniemi-Syrjänen A, Palosuo K, Marsh $\mathrm{J}$, Borres M, Kuitunen M, Pelkonen AS. Wheat allergy in children-new tools for diagnostics. Clinical \& Experimental Allergy. 2014 Nov; 44(11):1420-30.

[7] Gasbarrini G, Mangiola F. Wheat-related disorders: A broad spectrum of 'evolving' diseases. United European Gastroenterol J. 2014. Aug; 2(4): 254-62.

[8] Palosuo K. Update on wheat hypersensitivity. Curr Opin Allergy Clin Immunol. 2003 Jun; 3(3): 205-9.

[9] Urade R, Sato N, Sugiyama M. Gliadins from wheat grain: An overview, from primary structure to nanostructures of aggregates. Biophysical reviews. 2018 Apr 1; 10(2): 435-43.

[10] Clinical presentation, allergens, and management of wheat allergy. Quirce S, Boyano-Martínez T, Díaz-Perales A. Clinical presentation, allergens, and management of wheat allergy. Expert review of clinical immunology. 2016 May 3; 12(5): 563-72.

[11] Rostami Nejad M. Celiac Disease and Non-Celiac Gluten Sensitivity; Evidences and Differences. International Journal of Celiac Disease. 2013; 1(1): 6-7.

[12] Bascuñán KA, Roncoroni L, Branchi F, Doneda L, Scricciolo A Ferretti F, Araya M, Elli L. The 5 Ws of a gluten challenge for gluten-related disorders. Nutrition reviews. 2018 Jan 9; 76(2): 79-87. 